\title{
Levomilnacipran for the treatment of major depressive disorder: a review
}

\author{
This article was published in the following Dove Press journal: \\ Neuropsychiatric Disease and Treatment \\ 9 January 2015 \\ Number of times this article has been viewed
}

\author{
Gregory M Asnis ${ }^{1,2}$ \\ Margaret A Henderson ${ }^{2}$ \\ 'Department of Psychiatry \\ and Behavioral Sciences, Albert \\ Einstein College of Medicine, \\ ${ }^{2}$ Anxiety and Depression Clinic, \\ Montefiore Medical Center, Bronx, \\ New York, NY, USA
}

\begin{abstract}
Levomilnacipran (LVM, Fetzima ${ }^{\circledR}$ ) was recently approved by the US Food and Drug Administration for the treatment of major depressive disorder. It is a unique dual neurotransmitter reuptake inhibitor. In contrast with other selective serotonin norepinephrine reuptake inhibitors, including duloxetine, venlafaxine, and desvenlafaxine, it has greater selectivity for inhibiting norepinephrine reuptake than serotonin reuptake. Our review focuses on the efficacy, safety, and tolerability data for five double-blind, placebo-controlled, short-term studies and two longterm studies. In the short-term studies, LVM was found to be more effective than placebo in reducing depression (Montgomery-Åsberg Depression Rating Scale) scores as well as improving functional impairment (Sheehan Disability Scale) scores. Long-term studies found LVM to be similarly effective but in the only placebo-controlled long-term study, LVM was not significantly superior to placebo. LVM is fairly well tolerated, with the most common adverse events being nausea, headache, dry mouth, hyperhidrosis, and constipation. Discontinuation rates were mildly increased in those being treated with LVM (9\%) versus placebo (3\%). Adverse events were not dose-related except for urinary hesitancy and erectile dysfunction. LVM was weight neutral, was not toxic to the liver, and did not cause clinically significant QTc prolongation. Consistent with being a predominant potentiator of norepinephrine, pulse and blood pressure were significantly elevated by LVM but rarely induced tachycardia or hypertension. LVM is a relatively safe alternative antidepressant treatment with minimal drug-drug interactions. It is the only antidepressant that has in its labeling that it is not only effective in improving depression but also effective in improving impaired functioning. Whether this important effect on functioning is unique to LVM must be researched. In addition, whether LVM might be effective in norepinephrine-deficit depression, refractory depression, atypical depression, or seasonal depression is yet to be evaluated. Ultimately, head-to-head studies comparing LVM with other antidepressants will determine the place of LM in antidepressant treatment.
\end{abstract}

Keywords: levomilnacipran, antidepressant, clinical efficacy, functional impairment

\section{Introduction}

Although antidepressants clearly have been significantly effective in the treatment of major depressive disorder (MDD), ${ }^{1}$ they have also been disappointing, in that many patients fail to respond, only have a partial response, cannot continue treatment due to intolerable side effects, or relapse despite continuing initially successful antidepressant treatment. ${ }^{2,3}$ This was highlighted in the STAR*D (Sequenced Treatment Alternatives to Relieve Depression) study in which only approximately $30 \%$ of patients had a remission and 50\% had a clinical response (improvement of 50\% from baseline) to a 12- to 14-week course of citalopram, a selective serotonin reuptake inhibitor (SSRI). ${ }^{2,3}$ In addition, over $40 \%$ of patients had significant side effects. ${ }^{3}$ Lastly, even for patients who initially responded to treatment with citalopram, approximately $40 \%$ relapsed within one year of continued treatment. ${ }^{2-4}$ Thus, there is need for alternative
Correspondence: Gregory M Asnis Anxiety and Depression Clinic, Montefiore Medical Center, III East 210 th Street, Bronx, New York, NY 10467, USA

Tel +l 9175979408

Fax +17188824735

Email asnisarts@aol.com 
antidepressants that are more effective and better tolerated than the currently approved antidepressants.

Recently, levomilnacipran (1S, 2R-milnacipran; LVM; Fetzima $^{\circledR}$, Forest Pharmaceuticals Inc, New York, NY, USA), was approved by the US Food and Drug Administration for the treatment of MDD. It is an enantiomer of the racemic drug, milnacipran, which is approved for the treatment of MDD in Europe and Japan and for fibromyalgia in the USA..$^{5-7}$ Preclinical studies have found that LVM is a more potent inhibitor of norepinephrine and serotonin (50 and 13 times, respectively) than the less active enantiomer, F2696 (1R, 2S-). Furthermore, it has a better pharmacokinetic profile than F2696, having a longer elimination half-life with a higher maximal concentration and area under the curve. ${ }^{8}$ Thus, LVM is a dual neurotransmitter reuptake inhibitor of norepinephrine and serotonin. It is unique amongst other dual neurotransmitter reuptake inhibitors in that it predominantly potentiates norepinephrine over serotonin; it has over a 15-fold higher selectivity for norepinephrine versus serotonin reuptake inhibition compared with duloxetine, desvenlafaxine, or venlafaxine. ${ }^{8-10}$ Interestingly, both in vitro and in vivo animal studies suggest that, at higher doses, serotonergic activity increases so that inhibition of norepinephrine reuptake approaches that of inhibition of serotonin reuptake. LVM lacks affinity for other receptors, including the dopaminergic, adrenergic, histaminic, muscarinic, and opioid receptors. ${ }^{8}$

The pharmacokinetics of LVM follow linear dynamics between $25 \mathrm{mg} /$ day and $300 \mathrm{mg} /$ day. LVM has a half-life of approximately 12 hours, with a time to peak concentration of 6-8 hours. Absorption is not affected by food intake, and the drug is $22 \%$ bound to protein. Metabolism is primarily through cytochrome $3 \mathrm{~A} 4$. The latter can contribute to potential drug-drug interactions if the concomitant drug is a strong inhibitor of cytochrome $3 \mathrm{~A} 4$, such as ketoconazole, clarithromycin, or ritonavir. Therefore, in these situations, a maximal dose of $80 \mathrm{mg}$ is recommended. Excretion of LVM is predominantly via the kidney. Thus, the package insert suggests a reduced maximal dose of $80 \mathrm{mg}$ if moderate renal impairment exists (creatinine clearance 30-59 mL per minute) and $40 \mathrm{mg}$ if severe renal impairment exists (creatinine clearance $15-29 \mathrm{~mL}$ per minute). LVM should not be used in patients with end-stage renal disease. ${ }^{11}$

The purpose of this paper is to review the status of LVM, which was approved by the US Food and Drug Administration in July 2014, presenting an overview of its effectiveness, safety, and tolerability. Some speculation as to where LVM might fit in clinically is also presented.

\section{Treatment studies}

\section{Short-term studies}

Overall, there were five double-blind, placebo-controlled studies evaluating LVM during the acute phase of treatment (8-10 weeks)..$^{5,6,12-14}$ There was a single-blind, placebo, lead-in phase in four of the five studies ${ }^{5,12-14}$ (one study did not have a placebo lead-in $)^{6}$ of one week ${ }^{5,12-14}$ and a double-blind, downtaper period of one week in two trials $\mathrm{s}^{6,12}$ and 2 weeks in three trials. ${ }^{5,13,14}$ An extended-release (ER) form of LVM (the preparation which is approved as Fetzima in the USA), developed for once daily administration was used in these studies.

A total of 2,598 subjects entered the studies (1,588 on LVM ER and 1,032 on placebo). Patients were aged 18-80 years (mean age approximately 43 years) and predominantly female $(63.8 \%)$. The study population had a long history of depression with multiple episodes and were moderately to severely ill; about $80 \%$ had a history of recurrent depressive episodes, with $25 \%$ having a current depressive episode of 12 or more months, $46 \%$ having a history of MDD for at least 10 years, and the mean Montgomery-Åsberg Depression Rating Scale (MADRS) score at baseline was over 33. ${ }^{15}$ These studies consisted of two fixed-dose trials $\mathrm{s}^{5,12}$ and three flexible-dose trials. ${ }^{6,13,14}$ The dose ranged from $40 \mathrm{mg} /$ day to $120 \mathrm{mg} /$ day. All studies were USA-based except for one that took place in Europe, South Africa, and India. ${ }^{6}$ Four studies were Phase III ${ }^{5,12-14}$ and one study was Phase II. ${ }^{6}$

\section{Continuation phase of treatment}

Overall, there were two long-term studies, comprising one study that treated patients openly (not placebo-controlled) with LVM for 48 weeks $^{16}$ and one that was a 24 -week, placebo-controlled, relapse prevention study. ${ }^{17}$

The relapse prevention study treated patients openly with a flexible LVM dose (40-120 mg/day) for 12 weeks. Those patients who had a clinical response at weeks 10 and 12 , defined as a MADRS ${ }^{18}$ score of $\leq 12$ and a Clinical Global Impression-Illness ${ }^{19}$ score of $\leq 2$, were randomized to LVM versus placebo. Those who were randomized to placebo had a down-taper of LVM over one week; those who were randomized to LVM stayed on the same dose that they were on at the end of week 12 in the open-label study. Relapse was defined as a MADRS score of $\geq 22$ and an increase of $\geq 2$ points in the Clinical Global Impression score above baseline just prior to randomization. ${ }^{17}$

\section{Efficacy measures}

The primary efficacy measure for the short-term studies was change from baseline depression rating at the end of the study 
(week 8 for all studies, except Montgomery et $\mathrm{al}^{6}$ which was week 10) as assessed with the MADRS; the latter is a 10-item rating scale focusing on symptoms of depression. Each item gets a score of 0 to 6 , with a total MADRS score potentially ranging from 0 to $60 .{ }^{18}$ The least squares mean differences (LSMDs) between LVM and placebo (change in score from baseline to the end of the study) using a mixed-effect model for repeated-measures analyses was the main statistical model utilized. In addition, a number of secondary measures were also assessed, such as change in functionality, which was evaluated using the Sheehan Disability Scale (SDS), a self-rating scale. ${ }^{20}$ The latter included three subscales of functionality, ie, work/school, social life, and family life, with ratings ranging from 0 (not at all) to 10 (extremely). Thus, an SDS total score of 0-30 was derived by adding the scores of the three subscales. LSMDs were also assessed for the SDS results similar to the statistical evaluation applied for the primary efficacy variable, ie, change in depression scores. Response rates and remission rates were assessed for the MADRS and SDS scores. Response regarding the depression variable was defined as a $\geq 50 \%$ decline in the MADRS score from baseline to the end of treatment and remission was defined as a MADRS score of $\leq 10$ at the end of study. Response regarding the functionality variable was defined as a total SDS score of $\leq 12$ and all subscale scores of $\leq 4$ by the end of treatment; a functional remission was defined as a total SDS score of $\leq 6$ and all subscale scores of $\leq 2$ by the end of treatment.

\section{Efficacy results \\ Primary efficacy variable}

A pooled analysis of the total population (five short-term clinical trials) found LVM to be more effective than placebo (LSMD $-3.0, P<0.001){ }^{15}$ Four of the five clinical trials found LVM to be significantly more effective than placebo in improving depression (MADRS, Table 1). ${ }^{5,6,12,13}$ The one study that did not find a significant difference (LSMD -1.5 , $P=0.260$ ) did find that LVM had a numerically greater response than placebo (Table 1). ${ }^{14}$ The authors of that study suggested an explanation of these negative findings, ie, that although the LVM group showed an antidepressant response similar to that in the positive trials, the placebo group had a particularly marked antidepressant response (2-3 points lower MADRS score than the results of the other positive LVM trials). ${ }^{14}$ A marked placebo response is occasionally seen in clinical trials, which is known to be contributory to a lack of separation of the test drug from placebo and inconclusive results. ${ }^{21}$
An LSMD score difference of $>2$ has been described in the literature as noting a clinically meaningful difference between a test drug and placebo. ${ }^{22}$ Thus, the more than 3-point LSMD score differences between LVM and placebo found for the positive LVM trials ${ }^{5,6,12,13}$ suggest that LVM is indeed an effective antidepressant for shortterm use (8-10 weeks). The only long-term study that was placebo-controlled (a double-blind, placebo discontinuation study) found that the time to relapse was longer for patients on LVM versus placebo but was not significantly different $(P=0.165) .{ }^{17}$ The authors suggest that the unexpected negative findings probably relate to the low relapse rate of $20.5 \%$ seen in the placebo group (versus a relapse rate of $13.9 \%$ for the LVM group). The number of patients selected for the study in order to achieve statistical power was based on the assumption that $38 \%$ of the placebo group would relapse versus $20 \%$ of the LVM group. Clearly, the long-term LVM study may have been underpowered. Thus, the efficacy of LVM for long-term use is unclear at this point.

\section{Secondary efficacy variables}

A meta-analysis of the five short-term LVM studies found that the LVM group had a significantly greater response rate $(46 \%$ versus $36 \%, P<0.001)$ and remission rate $(28 \%$ versus $22 \%, P<0.05)$ regarding their depression (MADRS) score then the placebo group. ${ }^{15}$ The MADRS response rate and remission rate for LVM were significantly greater than placebo in four of the five LVM trials; ${ }^{5,6,12,13}$ the one trial that failed to show significant superiority of LVM over placebo had a greater placebo response rate (a rate of $34.8 \%$ ) than the others. ${ }^{14}$ Of the long-term studies, the openlabel, 48-week trial found a MADRS response rate of $73 \%$ and a remission rate of $53 \% .^{16}$

Functional impairment has recently become a focus of attention regarding antidepressant treatment of patients with MDD. Clearly, a successful treatment course must not only lead to symptomatic improvement but also lead to a normalization of functioning. Although symptomatic improvement is usually accompanied by improvement in functioning, the latter can still remain impaired. ${ }^{23}$ This appears to be an important clinical point in that euthymic patients who still have impaired functioning are less likely to have a full recovery and more likely to suffer recurrences. ${ }^{24}$ Recently, some investigators have suggested that antidepressants with potent noradrenergic mechanisms may be particularly helpful in normalizing impaired functioning in depressed patients partly due to their positive effect on cognitive functioning and concentration. ${ }^{25}$ Since LVM is unique in having a potent 
Table I Summary of five double-blind, placebo-controlled, short-term LVM studies

\begin{tabular}{|c|c|c|c|c|c|}
\hline Study & $\begin{array}{l}\text { LVM dose, fixed } \\
\text { or flexible }\end{array}$ & Duration & Subjects $(\mathrm{n})^{*}$ & $\begin{array}{l}\text { Age (years) } \\
\text { Percent female }\end{array}$ & $\begin{array}{l}\text { Outcome** } \\
\text { (MADRS and SDS) }\end{array}$ \\
\hline Montgomery et al ${ }^{6}$ & $75-100 \mathrm{mg} / \mathrm{flexible}$ & 10 weeks & $\begin{array}{l}\text { Placebo, } n=297 \\
\text { LVM, } n=276\end{array}$ & $\begin{array}{l}18-70 \text { years } \\
66 \%\end{array}$ & $\begin{array}{l}\text { MADRS }-4.2, P<0.001 \\
\text { SDS }-3.4, P<0.001\end{array}$ \\
\hline Asnis et $\mathrm{al}^{5}$ & $40-120 \mathrm{mg} / \mathrm{fixed}$ & 8 weeks & $\begin{array}{l}\text { Placebo, } \mathrm{n}=175 \\
\text { LVM, } 40 \mathrm{mg} / \text { day, } \mathrm{n}=176 \\
\text { LVM, } 80 \mathrm{mg} / \text { day, } \mathrm{n}=177 \\
\text { LVM, I } 20 \mathrm{mg} / \text { day, } \mathrm{n}=176\end{array}$ & $\begin{array}{l}18-65 \text { years } \\
63 \%\end{array}$ & $\begin{array}{l}\text { I) MADRS } \\
\text { LVM, } 40 \mathrm{mg} / \text { day }-3.2 ; P<0.05 \\
\text { LVM, } 80 \mathrm{mg} / \text { day }-4.0 ; P<0.0 \text { I } \\
\text { LVM, I } 20 \mathrm{mg} / \text { day }-4.9 ; P<0.00 \text { I } \\
\text { 2) SDS } \\
\text { LVM, } 40 \mathrm{mg} / \text { day }-1.4 ; \mathrm{NS} \\
\text { LVM, } 80 \mathrm{mg} / \text { day }-2.5 ; P<0.05 \\
\text { LVM, I } 20 \mathrm{mg} / \text { day }-2.6 ; P<0.05\end{array}$ \\
\hline Sambunaris et $\mathrm{al}^{13}$ & $40-120 \mathrm{mg} / \mathrm{flexible}$ & 8 weeks & $\begin{array}{l}\text { Placebo, } n=214 \\
\text { LVM, } n=215\end{array}$ & $\begin{array}{l}18-80 \text { years } \\
65 \%\end{array}$ & $\begin{array}{l}\text { I) MADRS }-3 . \mathrm{I}, P<0.0 \mathrm{I} \\
\text { 2) } \mathrm{SDS}-2.6, P<0.0 \mathrm{I}\end{array}$ \\
\hline Gommoll et al $\left.\right|^{14}$ & $40-120$ mg/flexible & 8 weeks & $\begin{array}{l}\text { Placebo, } n=18 \mid \\
\text { LVM, } n=174\end{array}$ & $\begin{array}{l}18-80 \text { years } \\
64 \%\end{array}$ & $\begin{array}{l}\text { I) MADRS }-I .5, N S \\
\text { 2) SDS }-0.6, N S\end{array}$ \\
\hline Bakish et al ${ }^{12}$ & $40-80 \mathrm{mg} /$ fixed & 8 weeks & $\begin{array}{l}\text { Placebo, } \mathrm{n}=185 \\
\text { LVM, } 40 \mathrm{mg} / \text { day, } \mathrm{n}=185 \\
\text { LVM, } 80 \mathrm{mg} / \text { day, } \mathrm{n}=187\end{array}$ & $\begin{array}{l}18-75 \text { years } \\
64 \%\end{array}$ & $\begin{array}{l}\text { I) MADRS } \\
\text { LVM, } 40 \mathrm{mg} / \text { day }-3.3 ; P<0.0 \text { I } \\
\text { LVM, } 80 \mathrm{mg} / \text { day }-3.1 ; P<0.0 \text { I } \\
\text { 2) SDS } \\
\text { LVM, } 40 \mathrm{mg} / \text { day }-1.8 ; P<0.05 \\
\text { LVM, } 80 \mathrm{mg} / \text { day }-2.7 ; P<0.0 \text { I }\end{array}$ \\
\hline
\end{tabular}

Notes: *Modified intent to treat population, number of patients who had safety data plus at least one post-baseline evaluation; **LSMD between treatment groups (LVM versus placebo) in change from baseline by the end of the study.

Abbreviations: LSMD, least squares mean difference; LVM, levomilnacipran; MADRS, Montgomery Åsberg Depression Rating Scale; SDS, Sheehan Disability Scale.

noradrenergic component and one's functioning is so important, SDS was assessed in the LVM trials.

In the overall study population (meta-analysis of the five short-term LVM studies), the mean change in SDS score (end of treatment minus baseline score) was significantly greater for LVM over placebo (LSMD -2.2, $P<0.001$ ). In addition, LVM was significantly more effective than placebo in each of the SDS subscales, ie, work/school (LSMD -0.6, $P<0.001$ ), social life (LSMD $-0.8, P<0.001$ ), and family life (LSMD $-0.6, P<0.001$, Figure 1). ${ }^{26}$ Four of the five LVM trials found that LVM had a significantly greater positive effect on functionality than placebo (Figure 1). ${ }^{5,6,12,13}$ Again, as was the case with the primary efficacy variable, ie, MADRS, the LVM study conducted by Gommoll et al failed to find that LVM was significantly more effective than placebo (LSMD -0.6 , not statistically significant). ${ }^{14}$

In summary, LVM is effective in improving impaired functioning and improves depressive symptoms in MDD. Whether LVM is more effective than other antidepressants that are not predominantly noradrenergic, such as other serotonin-norepinephrine reuptake inhibitors (SNRIs) or SSRIs, awaits clarification. One recent meta-analysis of duloxetine, another SNRI, found that an asynchrony existed between symptomatic remission and functional remission. Clinical remission frequently was not accompanied by a functional remission. ${ }^{27}$ Thus, LVM may be unique here.

\section{Clinical dimensions associated with LVM responsiveness}

In the five short-term ${ }^{5,6,12-14}$ and two long-term LVM studies, ${ }^{16,17}$ ie, a total of seven publications, no clear clinical dimensions were identified as being associated with LVM treatment response. Recently, a meta-analysis of the five short-term LVM studies by Montgomery et $\mathrm{al}^{15}$ and Sambunaris et $\mathrm{a}^{26}$ was conducted using a large database to evaluate whether various baseline clinical dimensions were related to the LVM clinical response (on depression ratings, MADRS scores, and SDS functionality scores). Baseline clinical dimensions assessed included demographics, symptom severity, and MDD history.

Regarding the antidepressant response to LVM, age was evaluated by breaking the groups into $<45$ years and $\geq 45$ years; $<60$ years and $\geq 60$ years. Significant effects of LVM on MADRS were seen in all age groups, with the group aged 60 years and older having the greatest response of all the age groups (LSMD -4.4, $P=0.002$ ). 


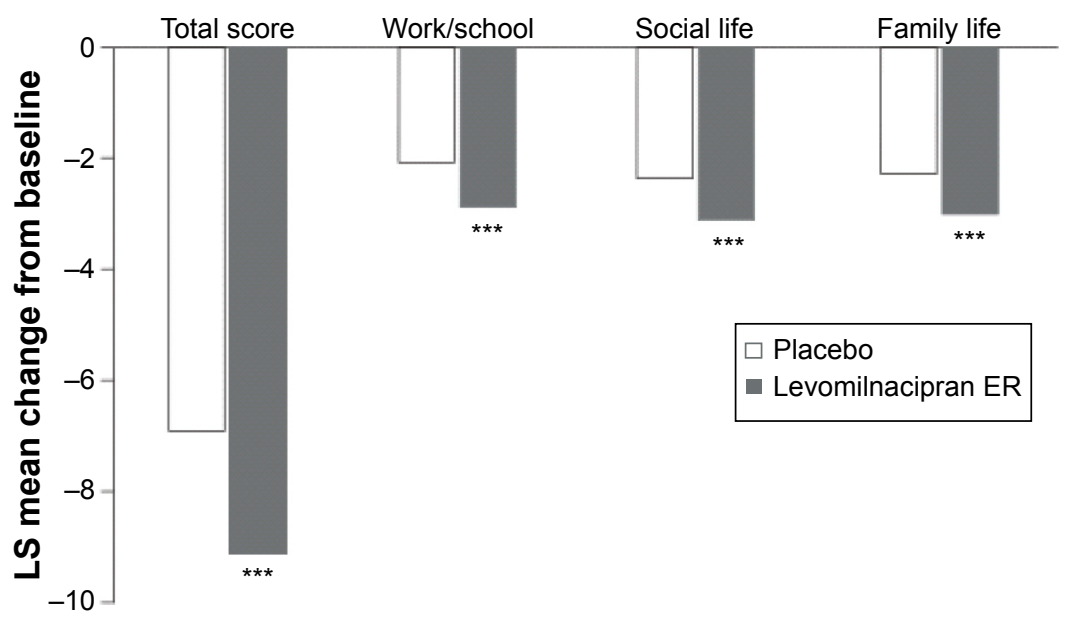

Figure I Meta-analysis of the five short-term LVM studies evaluating the effect of LVM versus placebo on SDS.

Notes: SDS total score and subscales: LS mean change from baseline to end of treatment in the overall population (mixed-effects model for repeated measures, intent to treat population). ${ }^{* * *} P<0.001$ versus placebo. Reproduced from Sambunaris A, Gommoll C, Greenberg WM. Efficacy of levomilnacipran extended-release in improving functional impairment associated with major depressive disorder: pooled analyses of five double-blind, placebo-controlled trials. Int Clin Psychopharmacol. 20I4;29:197-205. ${ }^{26}$

Abbreviations: LS, least squares; LVM, levomilnacipran; SDS, Sheehan Disability Scale; ER, extended-release.

In addition, drug-placebo differences in response rates were greatest in the group aged $\geq 60$ years. The latter group also had drug-placebo differences in remission rates that were higher than in the group aged $<45$ years but similar to the other age groups. This is of major interest in that the literature suggests that the elderly may not have as good an antidepressant effect compared with younger depressed populations. ${ }^{28}$ Thus, uniquely, the antidepressant effect of LVM does not appear to decrease in the elderly.

Regarding sex, both males and females had a greater LVM antidepressant response than placebo, with minimal sex differences in response and remission rates. ${ }^{15}$ This is an important point, in that the literature suggests a differential response to some antidepressants based on $\operatorname{sex}^{29}$ and that women tend to have a better response than men. ${ }^{30}$

Severity of illness was also evaluated for its effect on LVM antidepressant responsiveness. The baseline severity of illness of the depressed population in the five acute studies in general was predominantly moderate to severe, with $80 \%$ having a MADRS score $\geq 30$ and $40 \%$ having a MADRS score $\geq 35$. For these severely ill groups, significant improvement in MADRS over placebo occurred (for the group with MADRS score $\geq 30$ and for the group with MADRS score $\geq 35$, LSMD -2.9 and -3.2 respectively, $P<0.001$ ). Approximately $17 \%$ of the population had a more mild to moderately severe depression MADRS score of $<30$. LVM was also significantly more effective than placebo (LSMD - 33.5, $P<0.01$ ). Thus, LVM was effective in treating depression in both more severe and less severe populations of MDD. ${ }^{15}$ This is of particular interest in that some studies have suggested that antidepressants may be less effective in severe depression ${ }^{3}$ while other studies have suggested the contrary. ${ }^{31}$ A recent post hoc analysis of desvenlafaxine found that the latter was more effective than placebo, irrespective of the baseline depression scores. ${ }^{32}$ Thus, LVM also appears to be highly effective as an antidepressant in patients with a full range of severity of illness.

The clinical subgroups of current depressive episode $\geq 12$ months and duration of illness $<2$ years did not show a significant $L V M$ versus placebo difference; the difference in remission rates between LVM and placebo was $0.1 \%$ for the group with a current depressive episode $\geq 12$ months and $1.9 \%$ for the group with an illness duration of $<2$ years. Montgomery et al suggest that these negative findings could relate to the idea that the group with a longer duration of illness may be more refractory to antidepressants and, therefore, perhaps to LVM also, and that depressives with a short current episode ( $<2$ years) had a high placebo response rate, factors that could decrease the likelihood of finding drugplacebo differences. ${ }^{15}$

Regarding baseline clinical dimensions that may be associated with an effect of LVM on functional impairment, Sambunaris et al found that age, sex, functional impairment at baseline, and severity of illness at baseline were not significant factors. ${ }^{26}$

\section{Treatment-emergent adverse events}

Treatment-emergent adverse events were frequently reported for LVM and placebo (77\% versus $61 \%$, respectively) and were thought to be predominantly unrelated to the study 


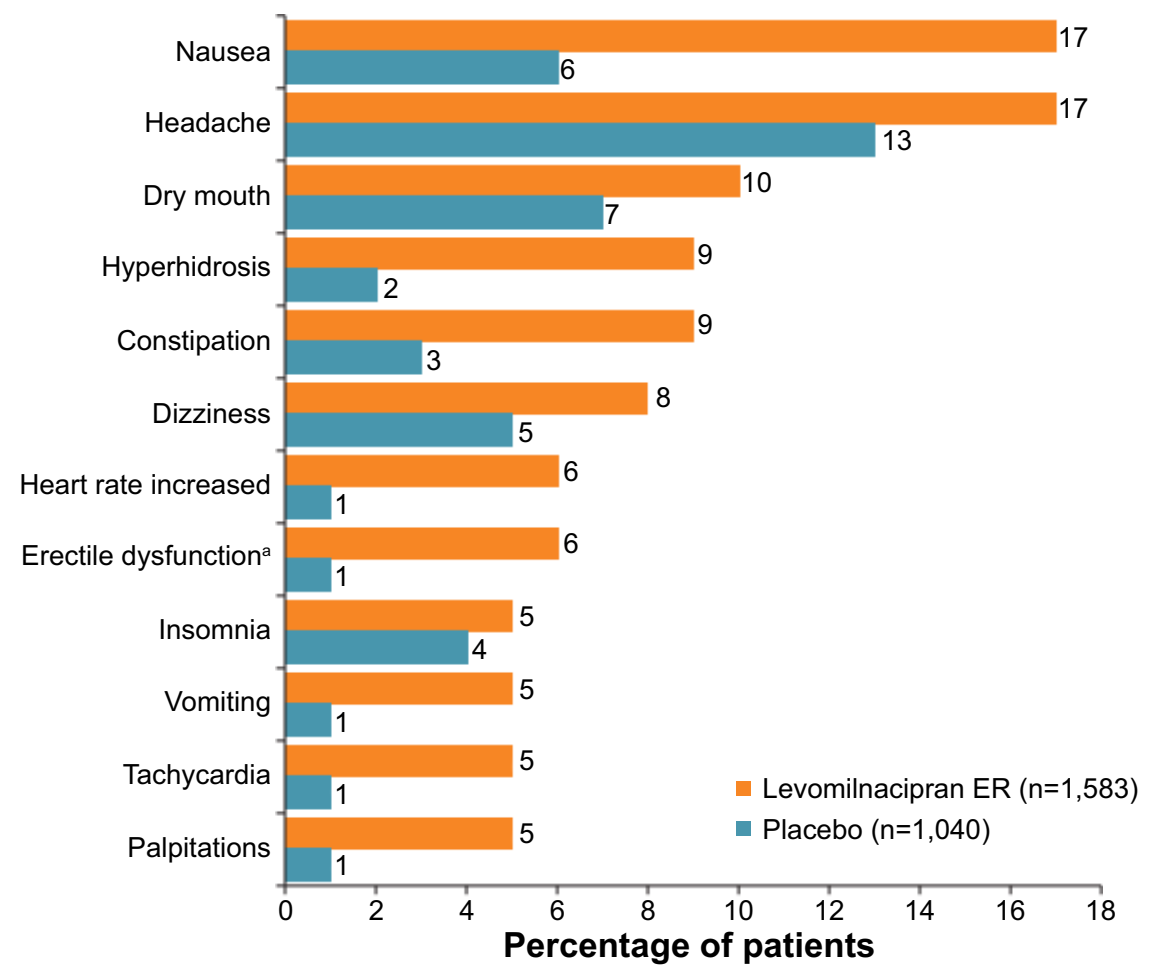

Figure 2 Common treatment-emergent adverse events (occurring in $\geq 5 \%$ of patients on levomilnacipran ER and $\geq 2 \%$ of patients on placebo.

Notes: ${ }^{a}$ Based on the number of males in the safety population (placebo, $n=374$; levomilnacipran ER, $n=577$ ). Reproduced from Thase ME, Greenberg WM, Bose A, Gummoll C, Chen C. Safety and tolerability of levomilnacipran SR in major depressive disorder: analysis of 5 short-term double-blind, placebo-controlled studies. Presented at the 166th Annual American Psychiatric Association Meeting, San Francisco, CA, USA, May 20, 2013.33

Abbreviation: ER, extended-release.

medication..$^{33}$ As can be seen in Figure 2, the incidence of many adverse events was greater for LVM than for placebo. The treatment-emergent adverse events were mainly of mild to moderate severity. The most common adverse events to LVM were nausea, headache, hyperhidrosis, constipation, and dizziness. Nausea and headache tended to occur early on in treatment and were frequently transient. ${ }^{11,33}$ Adverse events rarely led to discontinuation of medication. In the above short-term studies, $9 \%$ of LVM patients discontinued medication due to an adverse event in comparison with $3 \%$ of placebo patients; these rates are similar to those with other antidepressants, eg, venlafaxine $(12 \%)$ and fluoxetine $(7 \%){ }^{34}$ The only adverse event that led to discontinuation of $\geq 1 \%$ of patients on LVM was nausea ( $1.5 \%$ for LVM and $0.4 \%$ for placebo). ${ }^{11,33}$ The incidence of serious adverse events was similar for LVM $(0.7 \%)$ and placebo (1.3\%). No deaths occurred during the LVM trials. ${ }^{11,33}$

There were no dose-related adverse events noted for LVM in the dose range of 40-120 mg/day other than urinary hesitation ( $4 \%, 5 \%$, and $6 \%$ of patients on LVM $40 \mathrm{mg}, 80 \mathrm{mg}$, and $120 \mathrm{mg}$, respectively, versus $0 \%$ of patients on placebo) and erectile dysfunction $(6 \%, 8 \%$, and $10 \%$ of patients on LVM $40 \mathrm{mg}, 80 \mathrm{mg}$, and $120 \mathrm{mg}$, respectively, versus $2 \%$ of patients on placebo); higher doses were associated with an increased incidence of erectile dysfunction and urinary hesitation. ${ }^{11,33}$ Regarding the latter, males appear to be particularly vulnerable..$^{35-36}$

Although none of the cases of LVM-induced urinary hesitancy led to urinary retention or failure, cases where other antidepressants induced urinary hesitancy occasionally progressed rapidly to a medical emergency ${ }^{37}$ Thus, caution is advisable in patients who develop urinary hesitancy. The package insert suggests consideration of drug discontinuation if urinary hesitancy occurs. The package insert also suggests caution if using LVM in patients prone to obstructive urinary disorders. ${ }^{11}$ A prior history of a urinary obstructive disorder appears to predispose patients to urinary hesitancy secondary to antidepressants. ${ }^{36}$

\section{Cardiovascular effects}

LVM was associated with tachycardia, increased heart rate, and palpitations (Figure 2). In addition, increased blood pressure (BP), hypertension, and hypotension occasionally occurred. ${ }^{11,33}$ During the course of treatment in the short-term (8- to 10-week) studies, systolic and diastolic BP increased at the end of treatment by $3.0 \mathrm{mmHg}$ and $3.2 \mathrm{mmHg}$, respectively, in contrast with placebo, which was associated with a negligible effect on systolic BP $(-0.04 \mathrm{mmHg})$ 
and diastolic BP $(-0.0 \mathrm{mmHg})$. Further, $1.8 \%$ of LVM patients and $1.2 \%$ of placebo patients met broad criteria for hypertension defined a priori (systolic BP $\geq 140 \mathrm{mmHg}$ and an increase $\geq 15 \mathrm{mmHg}$ or diastolic $\mathrm{BP} \geq 90 \mathrm{mmHg}$ and an increase $\geq 10 \mathrm{mmHg}$ on at least three consecutive visits); $0.3 \%$ of LVM patients and $0.1 \%$ of placebo patients met strict criteria for hypertension defined a priori (systolic $\mathrm{BP} \geq 140 \mathrm{mmHg}$ and an increase $\geq 15 \mathrm{mmHg}$ and diastolic $\mathrm{BP} \geq 90 \mathrm{mmHg}$ and an increase $\geq 10 \mathrm{mmHg}$ on at least three consecutive visits). ${ }^{11}$ Hypotension was seen in $11.6 \%$ of patients on LVM versus $9.7 \%$ of patients on placebo. There was no dose relationship between LVM and BP findings. ${ }^{11,33}$ Regarding the long-term LVM studies, the open-label, 48-week trial found an increase in systolic BP of $3.9 \mathrm{mmHg}$ and an increase in diastolic BP of $3.3 \mathrm{mmHg} .{ }^{16}$ During the long-term, double-blind, placebo-discontinuation study, BP changes were minimal in the LVM and placebo groups. ${ }^{17}$ Thus, although LVM clearly can increase BP and occasionally induces a hypertensive state, this is relatively uncommon. If sustained hypertension develops, LVM may have to be discontinued. No data has been accumulated as yet in hypertensive states existing prior to initiating LVM treatment; thus, significant caution is suggested. It is strongly recommended that hypertensive patients should first be aggressively treated for their BP problems and hopefully become normotensive prior to initiating antidepressant treatment with LVM. Clinicians should carefully monitor BP prior to and periodically during treatment with LVM. ${ }^{11}$

In addition to having effects on BP, LVM is also known to affect heart rate; short-term studies found that the LVM group had an increase in heart rate of 7.4 beats per minute versus the placebo group, which had a decrease in heart rate of 0.3 beats per minute. ${ }^{11,33}$ During the long-term trials, there was an increase of 9.1 beats per minute in the open-label LVM study, ${ }^{16}$ and in the placebo-controlled study, there was an increase of 12.3 beats per minute for LVM and 3.6 beats per minute for placebo. ${ }^{17}$ The package insert suggests that if people experience an increased heart rate that is sustained, the drug may have to be discontinued or the event be adequately treated. Since minimal data exist on LVM in depressed patients with a cardiac rhythm disorder, the package insert recommends that patients with a cardiac rhythm disorder at baseline should be adequately treated for this condition prior to LVM therapy. ${ }^{11}$

The main reason for a focus on the potential of an antidepressant to prolong the QTc interval is that prolongation is associated with torsades de pointes and sudden cardiac death. ${ }^{38}$ A number of psychotropic medications, including antidepressants such as citalopram, venlafaxine, and mirtazapine, have been associated with QTc prolongation. . $^{39,40}$ Thus, knowing what effect LVM might have on the QTc interval is clinically relevant.

The QTcB (Bazett's correction) was mildly higher in the LVM group than in the placebo group, but none of the patients in the short-term studies experienced a potentially clinically significant prolongation $(>500 \mathrm{msec})$ of QTcB or QTcF (Fridericia correction). At doses that were 2.5 times the maximum recommended dose (300 mg), LVM did not elevate QTc to a clinically relevant extent. ${ }^{11}$ Since LVM is associated with an increased heart rate, the QTcF is a preferred measurement of ventricular repolarization since it adjusts for heart rate. In the long-term, open-label LVM study, one patient met the criteria for abnormal QTcB but had a normal QTcF value. ${ }^{16}$ In the placebo-controlled, double-blind, discontinuation study, no patient had an abnormal QTcB or QTcF interval; the QTcF interval on LVM was $-1.3 \mathrm{msec}$ and on placebo was $1.4 \mathrm{msec} .{ }^{17}$ Thus, it appears that LVM can be used without much concern for inducing a cardiac arrhythmia.

\section{Chemistry, hematological, and urinalysis changes}

Regarding the potential effect of antidepressants on chemistries, considerable attention has always been paid to liver function. Occasionally, antidepressants and other drugs can induce a drug-induced liver injury which, if accompanied by jaundice and hepatocellular damage, can lead to a liver transplant or death in over $10 \%$ of cases.$^{41}$ To help guard against this possible adverse event, Hy's law was established to predict liver failure. Hy's law includes having an alanine aminotransferase or aspartate aminotransferase level greater than three times the upper limit of normal, a total bilirubin greater than twice the upper limit of normal, and an alkaline phosphatase level less than twice the upper limit of normal. ${ }^{41}$ No patient in the LVM trials met Hy's law. Alanine aminotransferase and aspartate aminotransferase were found to be, at most, mildly higher in LVM-treated versus placebo-treated patients. ${ }^{5,12}$ Thus, LVM appears not to be toxic to the liver. Even when there is baseline pathology in the liver (mild, moderate, or severe liver impairment), the dose of LVM does not need to be modified since it is minimally metabolized by the liver. ${ }^{11}$ Further, the LVM-treated and placebo-treated groups did not differ regarding other chemistry, hematological findings, and urinalysis. ${ }^{11}$

\section{Body weight}

Four of the five short-term LVM trials reported weight change during the trial in their publications. ${ }^{5,12-14}$ There was 
a mean weight change of $-0.5 \mathrm{~kg}$ for those treated with LVM and $0.1 \mathrm{~kg}$ for those treated with placebo (Figure 3).

Regarding the long-term studies (Figure 4), there was a $-0.55 \mathrm{~kg}$ weight change by the end of treatment in the 48-week, open-label study. ${ }^{16}$ In the other long-term LVM study (a placebo-controlled, randomized, discontinuation study), there was a $-0.5 \mathrm{~kg}$ weight change for LVM versus a $0.5 \mathrm{~kg}$ weight change for placebo at the end of 24 weeks. ${ }^{17}$ Clearly, LVM was weight neutral both for short-term use ( 8 weeks) and long-term use (24-48 weeks).

\section{Suicidal behavior}

For the last decade, there has been careful scrutiny as to whether an antidepressant is associated with the development or worsening of suicidal ideation and behavior in patients with depression and other psychiatric disorders. Retroactive analysis of a number of short-term clinical trials with various SSRIs, SNRIs, and tricyclic antidepressants have reported a mild but significant increase in suicidal ideation and suicidal behavior in those treated with antidepressants versus placebo in children, adolescents, and young adults (aged 18-24 years) $)^{11,42}$ but a neutral to reduced suicidal risk for adults over the age of 24 years. ${ }^{11,43}$ In a review of the clinical trials leading up to this warning, no actual suicides were found in the database regarding children, adolescents, and young adults. ${ }^{11,42}$ In spite of the fact that the original database for this analysis only evaluated nine antidepressants in children and adolescents and eleven antidepressants in adults including some SSRIs, SNRIs and tricyclic antidepressants, all antidepressants, including LVM, have a black box warning. Regarding specific treatment-emergent suicidal ideation and suicidal behaviors in the short-term LVM studies, four of the five trials $\mathrm{s}^{5,12-14}$ evaluated and monitored suicidal ideation and behavior at baseline and during the treatment program using a structured rating instrument, the Columbia-Suicide Severity Rating Scale. ${ }^{44}$ The treatment-emergent adverse event of

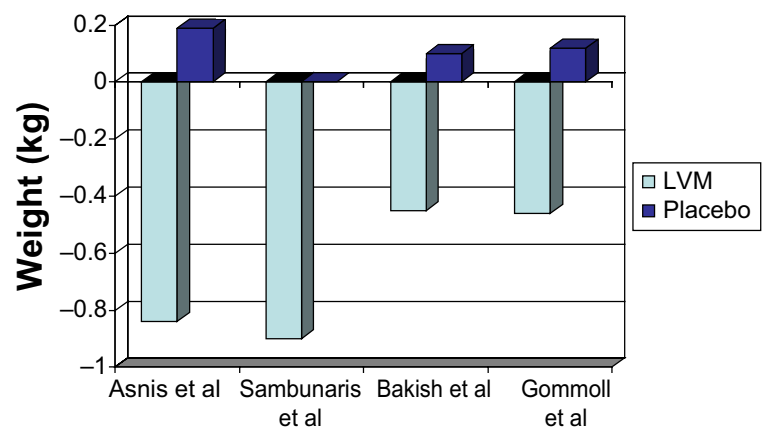

Figure 3 Weight changes on LVM versus placebo in short-term studies. Note: Data from. . $12-14^{-14}$

Abbreviation: LVM, levomilnacipran.

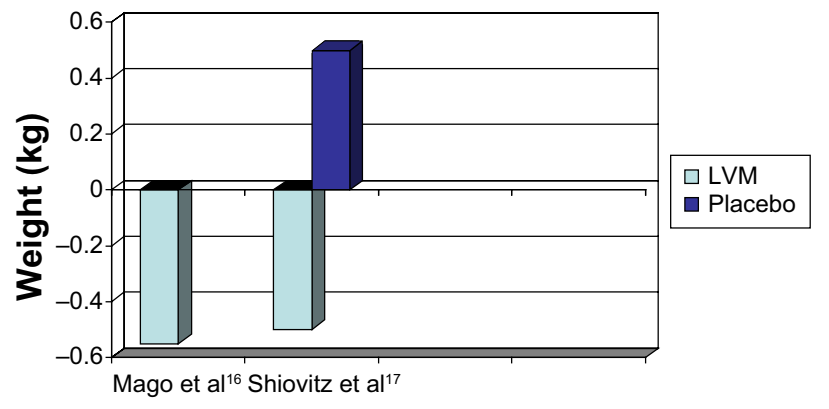

Figure 4 Weight changes on LVM versus placebo in long-term studies. Note: Data from. ${ }^{16,17}$

Abbreviation: LVM, levomilnacipran.

suicidal ideation and behavior was no different between LVM and placebo. ${ }^{11,33}$ Suicidal ideation worsened or developed in three patients taking LVM and in one patient on placebo, ${ }^{5,14}$ whereas suicidal behavior occurred in two patients on LVM and two patients on placebo. ${ }^{5,12}$ No completed suicides occurred in any of the short-term LVM studies. Thus, regarding antidepressant-induced suicidal ideation and behavior, LVM appears to be safe. The two long-term studies also found that LVM rarely induced suicidal ideation and behavior. ${ }^{16,17}$ The one long-term study that was placebo-controlled found that three patients $(2.7 \%)$ on placebo developed suicidal ideation versus eleven patients (4.8\%) on placebo. No suicidal behavior occurred in either treatment group. ${ }^{17}$ A note of caution should be made here. The LVM trials excluded patients who had a significant suicidal risk-prior suicide attempt in the past year or severe suicidal ideation during the screening period. It is possible that such at-risk patients may be more vulnerable to LVM (antidepressant)-induced worsening or development of suicidal ideation and behavior. Out of caution, the package insert states that clinicians must monitor carefully the risk of suicidal behavior, both prior to initiating and during LVM treatment, as is requested for all treatment with antidepressant medications in general. ${ }^{11}$

\section{Administration guidelines}

LVM is an ER preparation and is to be taken once a day. The package insert suggests that it be taken at the same time every day, and that it is not affected by food intake and should be swallowed whole ("not chewed, opened or crushed"). ${ }^{11}$ As with most medications that have nausea as a common side effect, we agree with Mago et al that LVM should be taken after the intake of food to possibly buffer such an effect. ${ }^{45}$ LVM comes in four capsule strengths, ie, $20 \mathrm{mg}, 40 \mathrm{mg}$, $80 \mathrm{mg}$, and $120 \mathrm{mg}$. The package insert suggests that the starting dose should be $20 \mathrm{mg} /$ day for a minimum of 2 days and increased by $20 \mathrm{mg} /$ day every 2 days, depending on tolerance 
and efficacy, up to a maximum dose of $120 \mathrm{mg} /$ day. The therapeutic dose is $40-120 \mathrm{mg} /$ day. ${ }^{11}$ Thus, dose increases can be made rather quickly; nonetheless, we suggest a somewhat slower upward titration of the dose since some of the potential adverse events are dose-dependent (urinary hesitancy, erectile dysfunction) and possibly can be avoided and/or minimized with a slower dose titration. In addition, it is somewhat unclear how effective "pushing the dose" is, since there is a question as to whether there is in fact a clear doseresponse relationship. A recent presentation by Asnis et al found that although LSMD scores appeared larger at higher doses for MADRS and SDS scores, there were no statistically significant differences between the lowest dose of $40 \mathrm{mg}$ and the highest dose of $120 \mathrm{mg} .{ }^{46}$ Clearly, many patients respond to lower doses, ie, $40 \mathrm{mg}$ and $80 \mathrm{mg}$, as was demonstrated in the two fixed-dose studies. ${ }^{5,12}$ One can always increase the dosage if lack of response becomes an issue.

When discontinuing LVM, the package insert suggests to gradually reduce the dose over time if possible in order to avoid and/or minimize "discontinuation symptoms". ${ }^{11} \mathrm{We}$ suggest that the discontinuation follow a slow down-taper of the medication from 1 to 2 weeks as was the design of the LVM clinical trials; if a patient develops any symptoms during this period, the down-taper can always be stretched out longer. "Discontinuation symptoms" have been well documented in the literature, occurring in about $20 \%$ of patients who suddenly discontinue their antidepressant. Discontinuation symptoms may include nausea, dizziness, headaches, and insomnia. ${ }^{47}$ Interestingly, the LVM trials found comparable rates of discontinuation symptoms between LVM and placebo. Nonetheless, the possibility of discontinuation symptoms exists. Thus, caution should be applied when discontinuing LVM.

\section{Is there a special role for LVM?}

How will LVM be used by mental health professionals? Will it target, eg, particular depressive symptoms? LVM has just been approved without comparator studies with other antidepressants, minimal post-clinical trial experience, and no post-marketing studies as yet. Nonetheless, it is possible to speculate on its possible usefulness in the treatment of MDD based partially on its uniqueness. LVM is an SNRI, but unique among SNRIs, in that it is the only SNRI that preferentially inhibits norepinephrine reuptake over serotonin reuptake. ${ }^{8}$ It might be a particularly effective antidepressant for a patient with MDD who has a hypothesized underlying norepinephrine deficit. The latter subgroup has been supported by biochemical and imaging studies. Further, the data suggest that norepinephrine-deficit depressions are associated with decreased concentration, low motivation, poor energy, inattention, poor self-care, and cognitive difficulties, whereas serotonin-deficit depressions are associated with anxiety, suicidality, and appetite disturbances. ${ }^{25,48}$ A secondary analysis of an LVM study by Montgomery et al found that LVM was superior to placebo for most depressive symptoms identified and rated by the MADRS, including those implicated in norepinephrine-deficit depression as well as serotonin-deficit depression. ${ }^{49}$ This broad effect may be due to its potentiating effect on serotonin despite its main effect being on norepinephrine. ${ }^{8}$

LVM not only has significant antidepressant effects but also has significant effects on improving and/or normalizing functioning in patients with MDD. Whether this relates to its predominant norepinephrine effects is unclear, although there are some data suggesting a major role of norepinephrine on functionality. ${ }^{25}$ Studies comparing LVM with other SNRIs and SSRIs regarding functionality are awaited. At this point, only LVM has in its labeling a statement that it not only significantly improves depressive symptoms but also significantly improves functional impairment.

LVM is an antidepressant that is fairly well tolerated, with most adverse events being of mild to moderate severity. Discontinuation rates are modest ( $9 \%$ for LVM versus $3 \%$ for placebo). ${ }^{11,33}$ The two main adverse events that lead to discontinuation by patients on antidepressants in general are weight gain and sexual dysfunction. ${ }^{50}$ Regarding LVM, it has been shown to be weight neutral in both short-term studies ${ }^{5,12-14}$ and long-term studies. ${ }^{16,17}$ In addition, spontaneous reports of sexual dysfunction were low, but in males, LVM did have a small increased incidence of erectile dysfunction (5.9\%), ejaculatory disorder (4.7\%), and testicular pain $(3.8 \%)$ when compared with placebo $(\leq 1 \%$ for each sexual dysfunction). ${ }^{11}$

LVM is easy to use. There are few drug-drug interactions other than the concomitant use of strong cytochrome $3 \mathrm{~A} 4$ inhibitors. It can be used safely in moderate and severe hepatic impairment and in mild renal impairment without any dose reductions. ${ }^{11}$

One potential problem for LVM is adverse events that are related to its noradrenergic mechanisms. There are significant increases in BP and pulse which can occasionally become clinically significant, necessitating periodic monitoring of vital signs. Patients who have hypertension and or arrhythmias should be stabilized prior to treatment. If that is not possible, an alternative antidepressant should be considered. In addition, urinary hesitancy, a dose-related adverse event, occasionally 
occurs (4\% for the $40 \mathrm{mg}$ dose, $5 \%$ for the $80 \mathrm{mg}$ dose, and $6 \%$ for the $120 \mathrm{mg}$ dose versus $0 \%$ for placebo). ${ }^{11,33}$ The latter appears to be predominantly related to norepinephrine; supporting this suggestion is the finding that other noradrenergic antidepressants like reboxetine that are also associated with urinary hesitancy have been successfully treated with an alpha-1-adrenoceptor antagonist. ${ }^{36}$ In addition, Asnis et al were successful in treating a few cases of LVM-induced urinary hesitancy with tamsulosin, an alpha-1-adrenoceptor antagonist (Asnis et al, unpublished data, 2014). Patients who have symptoms of urinary obstruction or even a history of such symptoms should consider an alternative antidepressant.

Although LVM appeared to significantly help anxiety symptoms in the LVM trials as measured by the MADRS (ie, the MADRS item for inner tension) and Hamilton Depression Rating Scale $\left(\mathrm{HAMD}_{17}\right.$, ie, the HAMD items of anxietypsychological, somatic symptoms-gastrointestinal, and somatic symptoms-general), ${ }^{49}$ what effect LVM has on comorbid anxiety disorders or other comorbid psychiatric diagnoses is unknown, since the presence of a comorbid psychiatric diagnosis was an exclusion criterion in three of the five LVM trials; ${ }^{5,6,14}$ unfortunately, the effect of allowable comorbid anxiety disorders, ie, social anxiety disorder, generalized anxiety disorder, and specific phobias, seen in two trials was never analyzed. ${ }^{12,13}$ What effect LVM might have on comorbid anxiety disorders is an important question, given that approximately $60 \%$ of patients with MDD have a comorbid anxiety disorder. ${ }^{51}$

In addition, although LVM was significantly superior to placebo in the short-term studies, it failed to be significant in the one placebo-controlled, double-blind, long-term study. ${ }^{16}$ Another study is currently underway to reassess this important issue.

Despite having a number of positive reasons to consider LVM early in treatment, the economics of LVM may be prohibitive for many patients. Since LVM at this point does not have a generic equivalent, antidepressants which have generic formulations may be necessary due to lack of insurance coverage and restricted formularies.

Since refractory depression is such a prevalent problem (33\% of patients with MDD fail to respond to a course of two sequential antidepressants), ${ }^{2,3}$ what effect LVM might have on refractory depression is an important question. The five shortterm LVM trials all excluded patients who failed to respond to two antidepressants for their current depressive episode. Thus, whether LVM is effective in refractory depression needs to be studied. In addition, the efficacy of LVM in atypical depression, "anxious depression", psychotic depression, and seasonal depression needs to be studied. The true place of LVM will be learned from head-to-head, placebo-controlled studies comparing LVM with other antidepressants.

\section{Disclosure}

GMA is on the speaker's bureaus for Forest Research Institute and Shire Pharmaceuticals, and has received clinical research grants from Shire Research Institute, Lunbeck, and Takeda. MAH has no conflicts of interest to declare.

\section{References}

1. American Psychiatric Association. Practice guidelines for the treatment of patients with major depressive disorder (third edition). Am J Psychiatry. 2010;167 Suppl:1-118.

2. Rush AJ, Trivedi MH, Wisniewski SR, et al. Acute and longer-term outcomes in depressed outpatients requiring one or several treatment steps: a STAR*D report. Am J Psychiatry. 2006;163:1905-1917.

3. Trivedi MH, Rush AJ, Wisniewski SR, et al. Evaluation of outcomes with citalopram for depression using measurement-based care in STAR*D: implications for clinical practice. Am J Psychiatry. 2006;163:28-40.

4. Nierenberg AA, Husain MM, Trivedi MH, et al. Residual symptoms after remission of major depressive disorder with citalopram and risk of relapse: a STAR*D report. Psychol Med. 2010;40:41-50.

5. Asnis GM, Bose A, Gommoll CP, Chen C, Greenberg WM. Efficacy and safety of levomilnacipran sustained release $40 \mathrm{mg}, 80 \mathrm{mg}$, or $120 \mathrm{mg}$ in major depressive disorder: a phase 3, randomized, double-blind, placebo-controlled study. J Clin Psychiatry. 2013;74:242-248.

6. Montgomery SA, Mansuy L, Ruth A, Bose A, Li H, Li D. Efficacy and safety of levomilnacipran sustained release in moderate to severe major depressive disorder: a randomized, double-blind, placebo-controlled, proof-of-concept study. J Clin Psychiatry. 2013;74:363-369.

7. Citrome L. Levomilnacipran for major depressive disorder: a systematic review of the efficacy and safety profile for this newly approved antidepressant - what is the number needed to treat, number needed to harm and likelihood to be helped or harmed? Int J Clin Pract. 2013;67: 1089-1104.

8. Auclair AL, Martel JC, Assié MB, et al. Levomilnacipran (F2695), a norepinephrine-preferring SNRI: profile in vitro and in models of depression and anxiety. Neuropharmacology. 2013;70:338-347.

9. Deecher DC, Beyer CE, Johnston G, et al. Desvenlafaxine succinate: a new serotonin and norepinephrine reuptake inhibitor. $J$ Pharmacol Exp Ther. 2006;318:657-665.

10. Blier P, Saint-André E, Hébert C, de Montigny C, Lavoie N, Debonnel G. Effects of different doses of venlafaxine on serotonin and norepinephrine reuptake in healthy volunteers. Int J Neuropsychopharmacol. 2007; 10:41-50.

11. Forest Pharmaceuticals, Inc. Fetzima (levominacipran extended-release capsules). United States Prescribing Information. Revised July 2014. Available from: http://www.frx.com/pi/fetzima_pi.pdf. Accessed November 2, 2014.

12. Bakish D, Bose A, Gommoll C, et al. Levomilnacipran ER $40 \mathrm{mg}$ and $80 \mathrm{mg}$ in patients with major depressive disorder: a phase III, randomized, double-blind, fixed-dose, placebo-controlled study. J Psychiatry Neurosci. 2014;39:40-49.

13. Sambunaris A, Bose A, Gommoll CP, Chen C, Greenberg WM, Sheehan DV. A phase III, double-blind, placebo-controlled, flexibledose study of levomilnacipran extended-release in patients with major depressive disorder. J Clin Psychopharmacol. 2014;34:47-56.

14. Gommoll CP, Greenberg WM, Chen C. A randomized, double-blind, placebo-controlled study of flexible doses of levomilnacipran ER (40-120 mg/day) in patients with major depressive disorder. J Drug Assess. 2014;3:10-19.

15. Montgomery SA, Gommoll SA, Chen C, Greenberg WM. Efficacy of levomilnacipran extended-release in major depressive disorder: pooled analysis of 5 double-blind, placebo-controlled trials. CNS Spectr. 2014;5: $1-9$.

16. Mago R, Forero G, Greenberg WM, Gommoll C, Chen C. Safety and tolerability of levomilnacipran ER in major depressive disorder: results from an open-label, 48-week extension study. Clin Drug Investig. 2013;33: 761-771. 
17. Shiovitz T, Greenberg WM, Chen C, Forero G, Gommoll C. A randomized, double-blind, placebo-controlled trial of the efficacy and safety of levomilnacipran ER 40-120 mg/day for prevention of relapse in patients with major depressive disorder. Innov Clin Neurosci. 2014;11:10-22.

18. Montgomery SA, Asberg M. A new depression scale designed to be sensitive to change. Br J Psychiatry. 1979;134:382-389.

19. Guy W. ECDEU Assessment Manual for Psychopharmacology. Clinical Global Impressions. DHEW Publication No. 76-338. Rockville, MD, USA: National Institute of Mental Health; 1976.

20. Sheehan DV, Harnett-Sheehan K, Raj BA. The measurement of disability. Int Clin Psychopharmacol. 1996;11 Suppl 3:89-95.

21. Khin NA, Chen YF, Yang Y, Yang P, Laughren TP. Exploratory_analyses of efficacy data from major depressive disorder trials submitted to the US Food and Drug Exploratory Administration in support of new drug applications. J Clin Psychiatry. 2011;72:464-472.

22. Montgomery SA, Moller HJ. Is the significant superiority of escitalopram compared to other antidepressants clinically relevant? J Clin Psychopharmacol. 2009;24:111-118.

23. Solomon DA, Leon AC, Endicott J, et al. Psychosocial impairment and recurrence of major depression. Compr Psychiatry. 2004;45:423-430.

24. Spijker J, Graaf R, Bijl RV, Beekman AT, Ormel J, Nolen WA. Functional disability and depression in the general population. Results from the Netherlands Mental Health Survey and Incidence Study (NEMESIS). Acta Psychiatr Scand. 2004;110:208-214

25. Moret C, Briley M. The importance of norepinephrine in depression. Neuropsychiatr Dis Treat. 2011;7 Suppl 1:9-13.

26. Sambunaris A, Gommoll C, Greenberg WM. Efficacy of levomilnacipran extended-release in improving functional impairment associated with major depressive disorder: pooled analyses of five double-blind, placebo-controlled trials. Int Clin Psychopharmacol. 2014;29:197-205.

27. Sheehan DV, Harnett-Sheehan K, Spann ME, Thompson HF, Prakash A. Assessing remission in major depressive disorder and generalized anxiety disorder clinical trials with the discan metric of the Sheehan Disability Scale. Int Clin Psychopharmacol. 2011;26:75-83.

28. Nelson JC, Delucchi K, Schneider LSJ. Efficacy of second generation antidepressants in late-life depression: a meta-analysis of the evidence. Am J Geriatr Psychiatry. 2008;16:558-567.

29. Kornstein SG, Schatzberg AF, Thase ME, et al. Gender differences in treatment response to sertraline versus imipramine in chronic depression. Am J Psychiatry. 2000;157:1445-1452.

30. Young EA, Kornstein SG, Marcus SM. Sex differences in response to citalopram: a STAR*D report. J Psychiatr Res. 2009;43:503-511.

31. Papakostas GI, Culpepper L, Fayad RS, Musgnung J, Guico-Pabia CJ Efficacy of desvenlafaxine $50 \mathrm{mg}$ compared with placebo in patients with moderate or severe major depressive disorder: a pooled analysis of six randomized, double-blind, placebo-controlled studies. Int Clin Psychopharmacol. 2013;28:312-321.

32. Papakostas GI, Fava M. Does the probability of receiving placebo influence clinical trial outcome? A meta-regression of double-blind, randomized clinical trials in MDD. Eur Neuropsychopharmacol. 2009; 19:34-40.

33. Thase ME, Greenberg WM, Bose A, Gummoll C, Chen C. Safety and tolerability of levomilnacipran SR in major depressive disorder: analysis of 5 short-term double-blind, placebo-controlled studies. Presented at the 166th Annual American Psychiatric Association Meeting, San Francisco, CA, USA, May 20, 2013.

Neuropsychiatric Disease and Treatment

\section{Publish your work in this journal}

Neuropsychiatric Disease and Treatment is an international, peerreviewed journal of clinical therapeutics and pharmacology focusing on concise rapid reporting of clinical or pre-clinical studies on a range of neuropsychiatric and neurological disorders. This journal is indexed on PubMed Central, the 'PsycINFO' database and CAS,
34. Nemeroff CB, Thase ME; EPIC 014 Study Group. A double-blind, placebo-controlled comparison of venlafaxine and fluoxetine treatment in depressed outpatients. J Psychiatr Res. 2007;41:351-359.

35. Demyttenaere K, Huygens R, Van Buggenhout R. Tamsulosin as an effective treatment for reboxetine-asociated urinary retention. Int Clin Psychopharmacol. 2001;16:353-355.

36. Kasper S, Wolf R. Successful treatment of reboxetine-induced urinary hesitancy with tamsulosin. Eur Neuropsychopharmacol. 2002;12: 119-122.

37. Aggarwal A, Khandelwal A, Jiloha RC. Milnacipran-associated urinary retention: a case report. J Clin Psychopharmacol. 2010;30:641.

38. Straus SM, Sturkenboom MC, Bleumink GS, et al. Non-cardiac QTcprolonging drugs and the risk of sudden cardiac death. Eur Heart J. 2005;26:2007-2012

39. Van Noord C, Straus SM, Sturkenboom MC, et al. Psychotropic drugs associated with corrected QT interval prolongation. J Clin Psychopharmacol. 2009;29:9-15.

40. Jasiak NM, Bostwick JR. A review of the risk of QT/QTe prolongation among newer non-SSRI antidepressants. Ann Pharmacother. 2014;48: $1620-1628$

41. Regev A, Bjornsson ES. Drug-induced liver injury: morbidity, mortality, and Hy's law. Gastroenterology. 2014;147:20-24.

42. Hammad TA, Laughren T, Racoosin J. Suicidality in pediatric patients treated with antidepressant drugs. Arch Gen Psychiatry. 2006; 63:332-339.

43. Stone M, Laughren T, Jones ML. Risk of suicidality in clinical trials of antidepressants in adults: analysis of proprietary data submitted to US Food and Drug Administration. BMJ. 2009;339:b2880.

44. Posner K, Brown GK, Stanley B, et al. The Columbia-Suicide Severity Rating Scale: initial validity and internal consistency findings from three multisite studies with adolescents and adults. Am J Psychiatry. 2011;168:1266-1277.

45. Mago R Mahajan R, Thase ME. Levomilnacipran: a newly approved drug for treatment of major depressive disorder. Expert Rev Clin Pharmacol. 2014;7:137-145.

46. Asnis GM, Gommoll CP, Chen C. Treating major depressive disorder with levomilnacipran ER: efficacy and tolerability across the dose range. Presented at the 167th Annual American Psychiatric Association Meeting, New York, NY, USA, May 5, 2014.

47. Warner CH, Bobo W, Warner C, Reid S, Rachal J. Antidepressant discontinuation syndrome. Am Fam Physician. 2006;74:449-456.

48. Nutt DJ. Relationship of neurotransmitters to the symptoms of major depressive disorder. J Clin Psychiatry. 2008;69 Suppl E1:4-7.

49. Montgomery SA, Mansuy L, Ruth AC, Li D, Gommoll C. The efficacy of extended-release levomilnacipran in moderate to severe major depressive disorder: secondary and post-hoc analyses from a randomized, double-blind, placebo-controlled study. Int Clin Psychopharmacol. 2014;29: 26-35.

50. Ashton AK, Jamerson BD, L Weinstein W, Wagoner C. Antidepressantrelated adverse effects impacting treatment compliance: results of a patient survey. Curr Ther Res Clin Exp. 2005;66:96-106.

51. Kessler RC, Berglund P, Demler O. The epidemiology of major depressive disorder: results from the National Comorbidity Survey Replication (NCS-R). JAMA. 20038;289:3095-3105.

and is the official journal of The International Neuropsychiatric Association (INA). The manuscript management system is completely online and includes a very quick and fair peer-review system, which is all easy to use. Visit http://www.dovepress.com/testimonials.php to read real quotes from published authors. 